\title{
Thin-section computed tomography- determined usual interstitial pneumonia pattern affects the decision-making process for resection in newly diagnosed lung cancer patients: a retrospective study
}

\author{
Naozumi Hashimoto ${ }^{1 * \dagger}$, Akira Ando ${ }^{1 \dagger}$, Shingo Iwano ${ }^{2}$, Koji Sakamoto ${ }^{1}$, Shotaro Okachi ${ }^{1}$, Asuka Matsuzaki ${ }^{1}$,
} Yu Okada ${ }^{1}$, Kenji Wakai ${ }^{3}$, Kohei Yokoi ${ }^{4}$ and Yoshinori Hasegawa ${ }^{1}$

\begin{abstract}
Background: There is only limited information on the impact of thin-section computed tomography (TSCT)-determined usual interstitial pneumonia (UIP) pattern in the decision-making for resection in newly diagnosed lung cancer patients.

Methods: In this retrospective analysis, data were reviewed from 499 newly diagnosed lung cancer patients who received bronchoscopy between 2010 and 2014. The clinical impact of TSCT-determined UIP pattern on the decision-making process for resection in this cohort was evaluated.

Results: The prevalence rate of TSCT-determined fibrosis was 14.8\% (74/499 cases), 86.5\% (64/74 cases) of which also had TSCT-determined emphysema. The fibrosis group comprised 40 patients with possible UIP and 34 patients with the UIP pattern. Among surgical candidates, the number of surgeries performed was lower in the fibrosis group (60.8\%) than in the normal and emphysema groups (84.7 and 77.3\%, respectively). Although the proportion of possible UIP did not differ between surgical candidates and patients with resected lung cancer, the proportion of UIP pattern in patients with resected lung cancer was decreased by $8.5 \%$, compared to the surgical candidates. Although measurement of diffusing capacity of the lung for carbon monoxide (DLCO) was performed in more than $97 \%$ of patients with thoracic surgery, only $58 \%$ of patients without thoracic surgery had DLCO measurement. Multivariate analysis showed that the finding of UIP pattern independently affects the decision-making process for thoracic surgery. The adjusted odds ratios for the comparison between the patients without fibrosis and the patients with UIP pattern was 0.266 (95\% confidence intervals: 0.087-0.812).
\end{abstract}

Conclusions: The presence of TSCT-determined UIP pattern might independently affect the decision-making process for proposing thoracic surgery with curative intent.

Keywords: Bronchoscopy, CPFE, Decision-making process, Thin-section CT, Thoracic surgery

\footnotetext{
* Correspondence: hashinao@med.nagoya-u.ac.jp

${ }^{\dagger}$ Equal contributors

${ }^{1}$ Department of Respiratory Medicine, Nagoya University Graduate School of

Medicine, 65 Tsurumai-cho, Showa-ku, Nagoya 466-8550, Japan

Full list of author information is available at the end of the article
} 


\section{Background}

There are increasing numbers of elderly with smoking history as well as lung cancer patients with chronic lung diseases such as chronic obstructive lung disease (COPD) and pulmonary fibrosis. Many studies suggest that spirometry-determined airflow obstruction is related to worse postoperative outcomes among resected lung cancer cases [1-5]. Therefore, severe airflow obstruction might independently affect the decision-making process for proposing thoracic surgery [6].

Chest thin-section computed tomography (TSCT) with a slice thickness of less than $2 \mathrm{~mm}$ has been commonly used for the qualitative and quantitative evaluation of pulmonary emphysema and/or fibrosis [7]. There is increasing awareness that the presence of emphysema or fibrosis clinically affects postoperative and survival outcomes for patients with resected lung cancer [8-11]. TSCT-determined usual interstitial pneumonia (UIP) pattern is a characteristic finding of idiopathic pulmonary fibrosis (IPF) which has a death rate worse than that of many cancers $[12,13]$. In patients with resected lung cancer, acute exacerbation of interstitial lung diseases might be associated with the finding of TSCTdetermined UIP pattern [9]. Although we recently demonstrated that the presence of TSCT-determined combined pulmonary fibrosis and emphysema (CPFE) yielded worse postoperative and survival outcomes in patients with resected lung cancer, less than $30 \%$ of patients with fibrosis had TSCT-determined UIP pattern among resected lung cancer cases [14]. Therefore, we hypothesized that TSCT-determined UIP pattern might affect the decision-making process for resection in newly diagnosed lung cancer patients. New therapeutic options for stable chronic lung diseases such as COPD/emphysema and pulmonary fibrosis have been utilized in the worldwide $[15,16]$. To establish appropriate therapeutic strategy for chronic lung diseases among newly diagnosed lung cancer patients, clinical impact of TSCTdetermined UIP pattern on the decision-making process for proposing thoracic surgery should be determined. Bronchoscopy is performed for most lung cancer patients before the lung cancer treatment decision is made $[17,18]$.

In the present study, we determined the clinical impact of TSCT-determined UIP pattern on the decisionmaking process for resection among 499 newly diagnosed lung cancer patients who received bronchoscopy.

\section{Methods}

\section{Population}

Patients with newly diagnosed lung cancer who underwent bronchoscopy at Nagoya University Hospital from January 2010 and December 2014 were the subjects of this retrospective study. The study was approved by the Institutional Review Board of Nagoya University Graduate School of Medicine (No 20140052-2).

\section{Collection of data on patient characteristics}

Information about patient characteristics, pathological diagnosis of lung cancers, and clinical staging of lung cancers, was obtained from hospital records as previously reported. Spirometry screening assessment was routinely performed when patients admitted to hospital for bronchoscopy [6]. Diffusing capacity of the lung for carbon monoxide (DLCO) was measured using the single breath-holding method and the Burrows' equation was utilized for DLCO [2]. Subjects were assigned to the COPD group, if they had airflow obstruction as determined by an FEV1/FVC ratio below 0.70 [6]. Severity of airflow limitation in COPD was determined according to the Global Initiative for Chronic Obstructive Lung Disease (GOLD) grade [6, 19]. Clinical staging of lung cancer was based on the tumor, node, and metastasis (TNM) staging using the standards of the Union International Contre le Cancer (UICC), 7th edition [20]. Histological type of adenocarcinoma, squamous cell carcinoma (Sq), large cell carcinoma (Large), small cell lung carcinoma (SCLC), and non-small cell lung carcinoma (NSCLC), and carcinoid, were determined according to the World Health Organization's classification [21].

\section{Assessment of emphysema and fibrosis on chest CT}

Involvement of emphysema and fibrosis was evaluated by TSCT as previously reported [14]. Axial TSCT images of the whole lung with a slice thickness of $0.5-1.0-\mathrm{mm}$ were reconstructed at the same increment by using a high-spatial frequency algorithm. After the initial interpretation by at least two radiologists, the evaluation was performed by a chest radiologist (SI) who had 20 years of experiences in reading thoracic CTs. For the present study, emphysema and fibrosis on chest TSCT were evaluated in accordance with the definition described by Cottin et al. [14, 22]. The severity of emphysema was also evaluated visually according to the Goddard classification as previously reported [14, 23]. The severity of fibrosis was classified visually into three categories as follows: 0 , normal; 1 , possible usual interstitial pneumonia (UIP) pattern and 2, UIP pattern $[13,14]$.

\section{Statistical analysis}

All data were checked for completeness, and the analyzed variables were tested for normality of distribution by the Shapiro-Wilk test. One-way analysis of variance (ANOVA) was used to compare normally distributed variables among the groups, and Kruskal-Wallis test was used to compare non-normally distributed variables. The t-test was used to compare normally distributed 
variables between the surgery and the non-surgery group subjects, and Mann-Whitney test was used to compare non-normally distributed variables. Comparisons of proportions among the groups were made using the $x^{2}$ test or Fisher exact test. Multivariable logistic regression models were prepared to estimate the decision-making factors for proposing thoracic surgery. Inclusion of variables in the models was based on existing knowledge of the factors for proposing thoracic surgery, including age, histology, severity of airflow obstruction, clinical stage, and severity of fibrosis [6]. Statistical analyses were performed with PASW Statistics version 24.0 software (SPSS Inc., Chicago, IL), and a two-sided $P$ value less than 0.05 was considered statistically significant.

\section{Results}

Demographic distribution of patient characteristics

Data from 596 patients with lung cancer who were sequentially registered and underwent bronchoscopy from August 2010 to July 2014 were obtained from hospital records. The study population excluded 72 patients who had not undergone pulmonary assessment by spirometry. Twenty-five patients (not evaluated by TSCT for the presence of emphysema and/or fibrosis, or who had received repetitive bronchoscopy) were also excluded from the study population. As a result, the study cohort comprised 499 patients (83.7\%). In total, 135 (27.1\%) patients showed emphysema without fibrosis. Overall, 74 (14.8\%) patients had a finding of fibrosis, and 64 (86.5\%) of these patients also had emphysema. The remaining 290 (58.1\%) subjects showed evidence of neither emphysema nor fibrosis in their chest CT examinations. Although CPFE might be considered by some as an entity that is distinct from either emphysema or fibrosis [24], patients with fibrosis and CPFE were combined into a fibrosis group for further analysis in this study. The characteristics of the 499 study patients are presented in Table 1. The mean age was 70.0 years. Overall, 348 patients were male and 375 had a history of smoking. Compared with the normal group, the emphysema and fibrosis groups were predominantly male and with a higher

Table 1 Patient Characteristics

\begin{tabular}{|c|c|c|c|c|c|}
\hline & $\begin{array}{l}\text { All cases } \\
(n=499)\end{array}$ & $\begin{array}{l}\text { Normal } \\
(n=290)\end{array}$ & $\begin{array}{l}\text { Emphysema } \\
(n=135)\end{array}$ & $\begin{array}{l}\text { Fibrosis } \\
(n=74)\end{array}$ & $P$ value \\
\hline Age, years $^{a}$ & $70.0(38-88)$ & $68.4(38-88)$ & $69.9(47-86)$ & $71.9(58-87)$ & 0.012 \\
\hline Gender, male & $69.7(348)$ & $55.5(161)$ & $88.1(119)$ & $91.9(68)$ & 0.001 \\
\hline History of smoking & $75.2(375)$ & $58.6(170)$ & $99.3(134)$ & $95.9(71)$ & 0.001 \\
\hline Diabetes & $20.4(102)$ & $17.2(50)$ & $22.2(30)$ & $29.7(22)$ & 0.049 \\
\hline Ischemic cardiac disease & $7.8(39)$ & $4.8(14)$ & $11.9(16)$ & $12.2(9)$ & 0.014 \\
\hline \multicolumn{6}{|l|}{ Spirometric variables } \\
\hline VC $(\%)^{b}$ & $105.8(20.3)$ & $109.3(20.6)$ & $108.4(19.2)$ & $104.9(17.8)$ & 0.208 \\
\hline \%FEV1 predicted ${ }^{b}$ & $101.0(24.2)$ & $105.3(24.4)$ & $95.0(22.0)$ & $104.7(17.6)$ & 0.001 \\
\hline FEV1/FVC below 0.7 & $46.9(234)$ & $39.3(114)$ & $68.1(92)$ & $37.8(28)$ & 0.001 \\
\hline $\begin{array}{l}\text { Severity of airway } \\
\text { obstruction }\end{array}$ & & & & & 0.001 \\
\hline Non-COPD & $53.1(265)$ & $60.7(176)$ & $31.9(43)$ & $62.2(46)$ & \\
\hline GOLD grade 1 & $32.3(161)$ & $26.6(77)$ & $44.4(60)$ & $32.4(24)$ & \\
\hline GOLD grade 2 & $12.6(63)$ & $10.0(29)$ & $22.2(30)$ & $5.4(4)$ & \\
\hline GOLD grade 3 & $2.0(10)$ & $2.8(8)$ & $1.5(2)$ & $0(0)$ & \\
\hline GOLD grade 4 & $0(0)$ & $0(0)$ & $0(0)$ & $0(0)$ & \\
\hline \multicolumn{6}{|l|}{ TSCT emphysema } \\
\hline Grade 0 & $60.1(300)$ & $100(290)$ & $0(0)$ & $13.5(10)$ & \\
\hline Grade 1 & $26.9(134)$ & $0(0)$ & $62.2(84)$ & $67.6(50)$ & \\
\hline Grade 2 & $10.2(51)$ & $0(0)$ & $28.9(39)$ & $16.2(12)$ & \\
\hline Grade 3 & $2.8(14)$ & $0(0)$ & $8.9(12)$ & $2.7(2)$ & \\
\hline \multicolumn{6}{|l|}{ TSCT fibrosis } \\
\hline Grade 0 & $85.2(425)$ & $100(290)$ & $100(135)$ & $0(0)$ & \\
\hline Grade 1 & $8.0(40)$ & $0(0)$ & $0(0)$ & $54.1(40)$ & \\
\hline Grade 2 & $6.8(34)$ & $0(0)$ & $0(0)$ & $45.9(34)$ & \\
\hline
\end{tabular}

$\mathrm{n}$ indicates number. ${ }^{\mathrm{a}}$ Data are shown as mean (range). ${ }^{\mathrm{b}}$ Data are shown as mean (standard deviation). All other data are shown as $\%$ (number) 
smoking history. Although more than $65 \%$ of the emphysema group had airflow obstruction (determined by an FEV1/FVC ratio below 0.7), less than $40 \%$ of the fibrosis group including patients with CPFE had significant airflow obstruction. The severity of emphysema in the fibrosis group was similar to that in the emphysema group and the proportion of emphysema grade 1 was significantly higher than those with emphysema grade 2 or 3 . More than $45 \%$ of the fibrosis group had grade 2 disease (UIP pattern).

\section{Tumor characteristics}

Overall, 211 patients had pathological stage I disease, 75 patients had stage II disease, and 182 patients had stage III or IV disease. The prevalence of adenocarcinoma, squamous cell carcinoma, and other type of histology were $58.1,25.7$, and $16.2 \%$, respectively. To evaluate the association of TSCT-determined emphysema and/or fibrosis with characteristics of lung cancer, pathological stage and histology were compared among the groups (Table 2). The proportion of patients with stage I disease was significantly higher in the normal group and lower in the emphysema and fibrosis groups. Although determining the clinical stage should be essential before proposing the therapeutic options for lung cancer, uncompleted clinical staging did not differ among the groups. Regarding the tumor histology, the prevalence of adenocarcinoma was significantly higher in the normal group, whereas squamous cell carcinoma was significantly higher in the emphysema and fibrosis groups.

Critical impact of the severity of TSCT-determined fibrosis on the decision to propose thoracic surgery with curative intent To explore whether the severity of TSCT-determined fibrosis might affect the decision to propose thoracic surgery with curative intent, patients at stage IIIB and IV were excluded from the analysis because they were not eligible for thoracic surgery. In addition, the patients with incomplete clinical staging or SCLC were also excluded. Overall, we evaluated data from 343 patients with lung cancer at stage IA to IIIA who underwent TSCT examination, spirometry, and bronchoscopy. These patients were subdivided according to whether they received thoracic surgery (273 cases) or not (70 cases). The characteristics, spirometric variables, and TSCT data for the patients with or without thoracic surgery are summarized in Table 3 . The existence of comorbidities including ischemic disease did not differ among the group. Although measurement of DLCO was performed in more than $97 \%$ of patients with thoracic surgery, only $58 \%$ of patients without thoracic surgery had DLCO measurement. Even among these surgical candidates, the number of surgeries performed was significantly lower in the fibrosis group $(60.8 \%, 28 / 46$ cases) than in the normal and emphysema groups $(84.7 \%, 177 /$ 209 cases; 77.3\%, 68/88 cases, respectively). More than $70 \%$ of patients with each emphysema grade received thoracic surgery (emphysema grade 1, 61/85 cases; grade 2, 25/34 cases; grade 3, 7/10 cases, respectively) (Table 3 and Fig. 1a). As a consequence, the proportion of each emphysema grade did not differ between surgical candidates and patients with resected lung cancer (Fig. 1a). Although more than $70 \%$ of patients with fibrosis grade 1 received thoracic surgery (17/24 cases), only $50 \%$ of patients with fibrosis grade 2 received it (11/22 cases) (Table 3 and Fig. 1b). Therefore, among patients with fibrosis and resected lung cancer, those with fibrosis grade 2 were decreased by $8.5 \%$, compared to the surgical candidates (Fig. 1b). Less than $50 \%$ of patients with

Table 2 Tumor characteristics

\begin{tabular}{|c|c|c|c|c|c|}
\hline & $\begin{array}{l}\text { All cases } \\
(n=499)\end{array}$ & $\begin{array}{l}\text { Normal } \\
(n=290)\end{array}$ & $\begin{array}{l}\text { Emphysema } \\
(n=135)\end{array}$ & $\begin{array}{l}\text { Fibrosis } \\
(n=74) \\
\end{array}$ & $P$ value \\
\hline Clinical stage & & & & & 0.053 \\
\hline । & $42.3(211)$ & $47.6(138)$ & $36.3(49)$ & $32.4(24)$ & \\
\hline$\|$ & $15.0(75)$ & $15.1(44)$ & $14.1(19)$ & $16.2(12)$ & \\
\hline III & $17.8(89)$ & $12.8(37)$ & $24.4(33)$ & $25.7(19)$ & \\
\hline IV & $18.6(93)$ & $17.9(52)$ & $19.3(26)$ & $20.3(15)$ & \\
\hline$N D^{a}$ & $6.2(31)$ & $6.6(19)$ & $5.9(8)$ & $5.4(4)$ & \\
\hline Histology & & & & & 0.001 \\
\hline Adenocarcinoma & $58.1(290)$ & $68.6(199)$ & $46.7(63)$ & $37.8(28)$ & \\
\hline Squamous cell carcinoma & $25.7(128)$ & $19.7(57)$ & $34.1(46)$ & $33.8(25)$ & \\
\hline Others $^{b}$ & $16.2(81)$ & $11.7(34)$ & $19.3(26)$ & $28.4(21)$ & \\
\hline Thoracic surgery & & & & & 0.002 \\
\hline yes & $55.9(279)$ & $62.3(180)$ & $51.1(69)$ & $40.5(30)$ & \\
\hline
\end{tabular}

$\mathrm{n}$ indicates number. All data are shown as \% (number)

${ }^{a} N D$ includes not determined

b Others include Large, SCLC, NSCLC and carcinoid 
Table 3 Patient and tumor characteristics in the thoracic surgery and non-thoracic surgery groups

\begin{tabular}{|c|c|c|c|c|}
\hline & all cases $(n=343)$ & non-surgery $(n=70)$ & surgery $(n=273)$ & $p$ value \\
\hline$\overline{\text { Age, years }}{ }^{a}$ & $69.8(38-88)$ & $70.7(50-86)$ & $68.8(38-88)$ & 0.001 \\
\hline Gender, male & $68.0(233)$ & $75.7(53)$ & $65.9(180)$ & 0.118 \\
\hline History of smoking & $72.3(248)$ & $80.0(56)$ & $70.3(192)$ & 0.107 \\
\hline Diabetes & $21.0(72)$ & $28.6(20)$ & $19.0(52)$ & 0.810 \\
\hline Ischemic disease & $7.9(27)$ & $12.9(9)$ & $6.6(18)$ & 0.083 \\
\hline \multicolumn{5}{|l|}{ Spirometric variables } \\
\hline$V c^{b}$ & $109.0(20.0)$ & $101.8(25.3)$ & $111.2(19.0)$ & 0.001 \\
\hline$\%$ FEV1 predicted ${ }^{b}$ & $104.1(23.5)$ & $94.2(24.7)$ & $106.2(22.6)$ & 0.011 \\
\hline FEV1/FVC below 0.7 & $43.7(150)$ & $50(35)$ & $42.1(115)$ & 0.236 \\
\hline DLCO, performed & $89.8(308)$ & $58.6(41)$ & $97.8(267)$ & 0.001 \\
\hline DLCO & $108.0(28.8)$ & $96.3(34.7)$ & $109.9(27.5)$ & 0.021 \\
\hline Severity of airway obstruction & & & & 0.049 \\
\hline Non-COPD & $56.3(193)$ & $50.0(35)$ & $57.9(158)$ & \\
\hline GOLD grade 1 & $32.9(113)$ & $37.1(26)$ & $31.9(87)$ & \\
\hline GOLD grade 2 & $9.0(31)$ & $7.2(5)$ & $9.5(26)$ & \\
\hline GOLD grade 3 & $1.7(6)$ & $5.7(4)$ & $0.7(2)$ & \\
\hline GOLD grade 4 & $0(0)$ & $0(0)$ & $0(0)$ & \\
\hline Thin section $\mathrm{CT}$ & & & & 0.001 \\
\hline Normal & $60.9(209)$ & $45.7(32)$ & $64.8(177)$ & \\
\hline Emphysema & $25.7(88)$ & $28.6(20)$ & $24.9(68)$ & \\
\hline Fibrosis & $13.4(46)$ & $25.7(18)$ & $10.9(28)$ & \\
\hline Severity of emphysema & & & & 0.065 \\
\hline Grade 0 & $62.4(214)$ & $48.6(34)$ & $65.9(180)$ & \\
\hline Grade 1 & $24.8(85)$ & $34.3(24)$ & $22.3(61)$ & \\
\hline Grade 2 & $9.9(34)$ & $12.8(9)$ & $9.2(25)$ & \\
\hline Grade 3 & $2.9(10)$ & $4.3(3)$ & $2.6(7)$ & \\
\hline Severity of fibrosis & & & & 0.002 \\
\hline Grade 0 & $86.6(297)$ & $74.3(52)$ & $89.7(245)$ & \\
\hline Grade 1 & $7.0(24)$ & $10.0(7)$ & $6.2(17)$ & \\
\hline Grade 2 & $6.4(22)$ & $15.7(11)$ & $4.0(11)$ & \\
\hline Clinical stage & & & & 0.001 \\
\hline । & $60.6(208)$ & $37.1(26)$ & $66.7(182)$ & \\
\hline$\|$ & $21.3(73)$ & $15.7(11)$ & $22.7(62)$ & \\
\hline III & $18.1(62)$ & $47.1(33)$ & $10.6(29)$ & \\
\hline Histology & & & & 0.006 \\
\hline Adenocarcinoma & $62.7(215)$ & $48.6(34)$ & $66.3(181)$ & \\
\hline Squamous cell carcinoma & $28.9(99)$ & $44.3(31)$ & $24.9(68)$ & \\
\hline Others $^{c}$ & $8.5(29)$ & $7.1(5)$ & $8.8(24)$ & \\
\hline
\end{tabular}

$\mathrm{n}$ indicates number. ${ }^{\mathrm{a}}$ Data are shown as mean (range). ${ }^{\mathrm{b}}$ Data are shown as mean (standard deviation). ${ }^{\mathrm{C}}$ Others include Large, SCLC, NSCLC and carcinoid. All other data are shown as \% (number)

stage III disease received thoracic surgery. More than $80 \%$ of patients with adenocarcinoma received thoracic surgery, but more than $30 \%$ of patients with squamous cell carcinoma did not. We evaluated the decisionmaking factors for proposing thoracic surgery (Table 4).
Although there were no significant relative odds ratios (ORs) for the comparison between the patients with fibrosis grade 0 and grade 1 , the relative ORs for the comparison between the patients with fibrosis grade 0 and grade 2 showed significant confidence intervals 


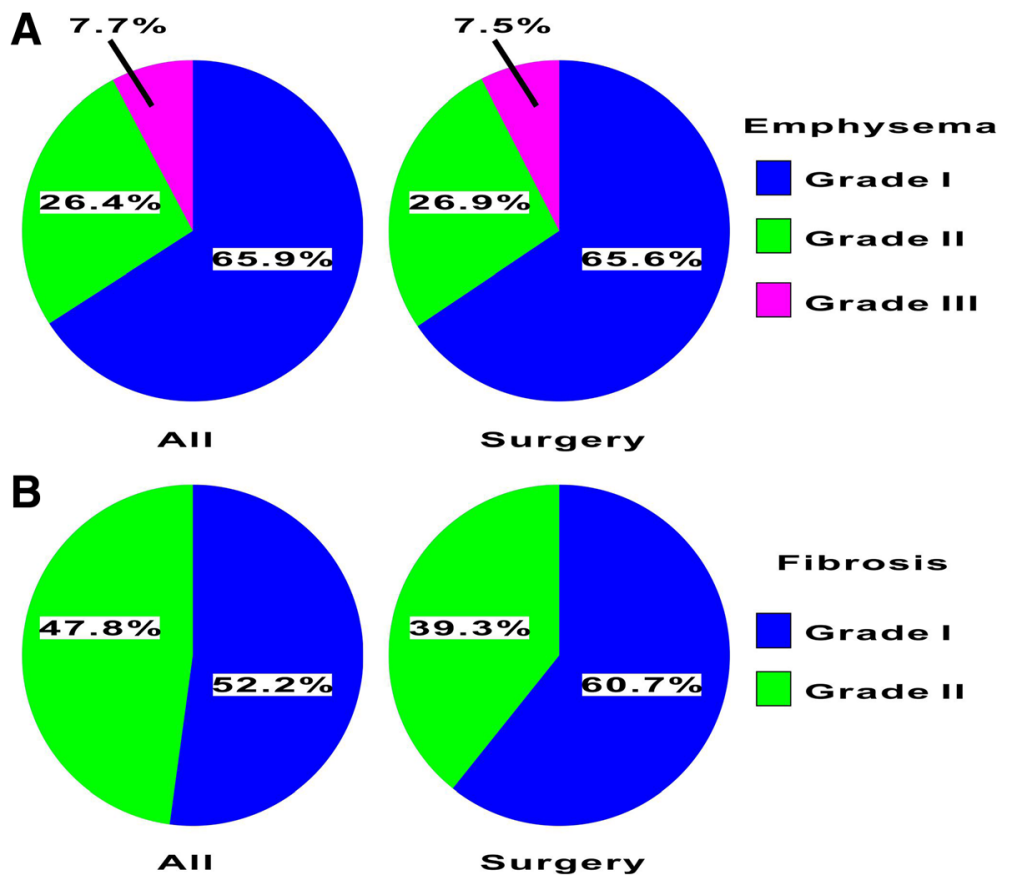

Fig. 1 Population of severity of emphysema and fibrosis. a The left panel shows emphysema severity among emphysema patients awaiting thoracic surgery with curative intent. The right panel shows emphysema severity in emphysema patients who received thoracic surgery. Blue, emphysema grade 1; green, emphysema grade 2; pink, emphysema grade 3. $\mathbf{b}$ The left panel shows fibrosis severity among fibrosis patients awaiting thoracic surgery with curative intent. The right panel shows fibrosis severity among fibrosis patients who received thoracic surgery. Blue, fibrosis grade 1; green, fibrosis grade 2

Table 4 Univariate and multivariate analysis of independent factors in decision-making process for proposing thoracic surgery with cure intent

\begin{tabular}{|c|c|c|c|c|c|c|}
\hline Variables & Unadjusted Odds Ratio & $95 \% \mathrm{Cl}$ & $P$ value & Adjusted Odds Ratio & $95 \% \mathrm{Cl}$ & $P$ value \\
\hline Age (per year) & 0.927 & $0.893-0.996$ & 0.001 & 0.883 & $0.840-0.927$ & 0.001 \\
\hline \multicolumn{7}{|l|}{ Histology } \\
\hline Adenocarcinoma & reference & & & reference & & \\
\hline Squamous cell carcinoma & 0.412 & $0.235-0.722$ & 0.020 & 0.589 & $0.287-1.207$ & 0.148 \\
\hline Others $^{\mathrm{a}}$ & 0.902 & $0.322-2.528$ & 0.844 & 2.258 & $0.565-9.027$ & 0.249 \\
\hline
\end{tabular}

Severity of airflow obstruction

\begin{tabular}{llllll} 
Non-COPD & reference & \multicolumn{3}{c}{ reference } \\
GOLD grade 1 & 0.741 & $0.419-1.312$ & 0.304 & 1.056 & $0.516-2.160$ \\
GOLD grade2 & 1.152 & $0.413-3.210$ & 0.787 & 1.500 & $0.428-5.259$ \\
GOLD grade 3 & 0.111 & $0.020-0.629$ & 0.013 & 0.049 & 0.527
\end{tabular}

Clinical stage

। reference

$\| \quad 0.805$

III $\quad 0.126$

Severity of fibrosis

$\begin{array}{ll}\text { Grade } 0 & \text { reference } \\ \text { Grade } 1 & 0.515 \\ \text { Grade } 2 & 0.212\end{array}$

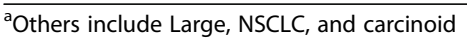


(CIs). When the relative ORs for the comparison between the patients with fibrosis grade 0 and grade 2 were adjusted for age, histology, clinical stage, and airflow obstruction, multivariate analysis showed a significant relative OR value of 0.266 (95\% CI: 0.087-0.812) (Table 4). Age, GOLD grade 3 airflow obstruction, and clinical stage III-but not squamous cell carcinomaremained to be independent decision-making factors for thoracic surgery after the adjustment (Table 4).

\section{Discussion}

This is the first study showing how the finding of TSCTdetermined UIP pattern affects the decision-making process for proposing resection among newly diagnosed lung cancer patients receiving bronchoscopy.

Technical progress in the chest TSCT examination has facilitated a more precise evaluation of existence and severity of emphysema and fibrosis. We recently demonstrated that the presence of TSCT-determined CPFE might predict worse postoperative and survival outcomes among patients with resected lung cancer [14]. In the previous study, more than $10 \%$ of patients with resected lung cancer were found to have fibrosis, $75 \%$ of whom had concurrent findings of emphysema. As a consequence, the prevalence of CPFE was 8.3\% [14]. Our present data showed that $14.8 \%$ of the newly diagnosed lung cancer patients with bronchoscopy had fibrosis; $86.5 \%$ of these also had TSCT-determined emphysema. As a consequence, the prevalence of CPFE was $12.8 \%$. Taken together, our data strengthens the theory that a TSCT examination at diagnosis for lung cancer successfully detects the presence of emphysema and fibrosis. In terms of the severity of emphysema in the patients with emphysema or CPFE, and in common with resected lung cancer cases [14], the proportion with emphysema grade 1 was significantly higher than those with emphysema grade 2 or 3 . The previous data showed that the proportion of UIP pattern was $22.3 \%$ in patients with fibrosis and resected lung cancer (17/76 cases) [14]. On the other hand, our present study demonstrated that the proportion of UIP pattern was $45.9 \%$ in the fibrosis group with newly diagnosed lung cancer (34/74 cases).

Whether the decision-making process involved in deciding therapeutic management options for lung cancer might be independently affected by the existence and severity of fibrosis in patients with lung cancer remains unclear. Therefore, we analyzed data from 343 patients with lung cancer at stage IA to IIIA because these patients are generally eligible for thoracic surgery with curative intent $[6,20,25]$. DLCO measurement is recommended for screening in the patients undergoing thoracic surgery, according to the European Respiratory Society (ERS) and the European Society of Thoracic Surgery (ESTS) clinical guideline [26]. DLCO is also a well-known survival predictor for patients with IPF and CPFE [27, 28]. Our data showed that DLCO measurement was not performed in more than $40 \%$ of surgical candidates missing thoracic surgery. Recent studies suggest that DLCO might be closely associated with the existence and extent of chest CT-detected emphysema and fibrosis [29, 30]. CPFE often involves upper lobe emphysema and lower lobe fibrosis [24]. The finding of TSCT-determined UIP pattern might affect survival in patients with CPFE [31]. DLCO measurement was performed for all five fibrosis patients, whereas more than $20 \%$ of CPFE patients did not have DLCO measurement (8/41 cases). Coexistence of TSCT-determined emphysema and fibrosis might affect the decision-making process for DLCO measurement with regards to postoperative residual lung function [32]. The previous study suggested that \%DLCO, not TSCT-determined UIP pattern, did not have a significant and independent association with acute exacerbation incidence of interstitial lung diseases in patients with resected lung cancers [9]. Thus, another possibility might be due to insufficient evidence to show the importance of DLCO measurement for lung cancer treatment. Finally, we evaluated whether fibrosis severity might be an independent factor affecting decisions to propose thoracic surgery with curative intent. Our previous study showed that more severe airway obstruction (defined as GOLD grade 3), advanced clinical staging, and higher age, were independent factors associated with the decision to perform thoracic surgery [6]. Our present study strengthened the conclusion that these factors are critical and independent of the thoracic surgery decision. Furthermore, multivariate analysis showed that the TSCT-determined UIP pattern independently affects the decision-making process for thoracic surgery. Finding of honeycombing with or without traction bronchiectasis is critical for making a definite diagnosis of UIP [13]. Thus, coexistence of TSCT-determined emphysema and UIP pattern fibrosis might also affect the decision-making process for thoracic surgery with regards to postoperative residual lung function [14, 32].

This study was based on a retrospective analysis of data from consecutive newly diagnosed lung cancer patients who received bronchoscopy at a single institution. Although retrospective analysis might have several limitations to determine the hypothesis, these dataincluding 83.7\% (499/596 patients) of all patients-are likely to minimize the possible contribution of selection bias due to different entry criteria for thoracic surgery [26]. We did not obtain pathologic confirmation of the fibrosis pattern from resected lung specimens. One reason is that the definition of CPFE was based on CT findings [24]. Another reason is that this study is aimed to evaluate the impact of TSCT-determined emphysema 
and fibrosis on the decision-making process for the treatment of lung cancer. Although the portion of lung resection might affect postoperative outcomes in resected lung cancer patients with fibrosis $[9,11]$, the portion of lung resection was not applied to our multivariate analysis. The decision for the portion of lung resection is usually made for surgical candidates who received preoperative spirometric assessment including DLCO [26]. Nevertheless, more than $40 \%$ of surgical candidates missing thoracic surgery did not receive DLCO measurement before the decision for the portion of lung resection.

More inclusive consideration for surgical resection with curative intent in lung cancer patients with chronic lung diseases should be required because limited surgical resections or nonsurgical therapeutic options might provide inferior survival compared with resection with curative intent. Recent studies show that multidisciplinary team management of lung cancer might improve survival outcomes [33, 34]. Furthermore, new therapeutic options for stable chronic lung diseases such as COPD/emphysema and pulmonary fibrosis have been utilized in the worldwide $[15,16]$. This study provides a basis for further investigation into determining optimal management for lung cancer patients with chronic lung diseases through multidisciplinary team involvement with pulmonary specialists.

\section{Conclusion}

The presence of TSCT-determined UIP pattern might independently affect the decision-making process for proposing thoracic surgery with curative intent.

\section{Acknowledgements}

Not applicable.

\section{Funding}

This work was supported by a grant to the Diffuse Lung Diseases Research Group from the Ministry of Health, Labour and Welfare, Japan [Grants; H26Nanchi-Ippan-065 and H29-Nanchi-Ippan-023].

\section{Availability of data and materials}

The raw data used in the present study were obtained from clinical records of participating patients and were included in a database after anonymization. The datasets used and/or analyzed during the current study are available from the corresponding author on reasonable request.

\section{Authors' contributions}

$\mathrm{NH}, \mathrm{AA}, \mathrm{KY}$, and $\mathrm{YH}$ had full access to all of the data in the study and are responsible for the integrity of the data and the accuracy of the data analyses. $\mathrm{NH}$ : contributed to develop the study conception, data collection, data analysis, manuscript drafting including revision, and final manuscript approval. AA: contributed to perform data collection, data analysis, and final manuscript approval. SI: contributed to the analysis of the TSCT examination findings, critical manuscript revision, and final manuscript approval. AM, YO, KS and SO: contributed to data collection, critical manuscript revision, and final manuscript approval. KW: contributed to the development of the analytic concept, the support for data analyses, critical manuscript revision, and final manuscript approval. KY and $\mathrm{YH}$ : contributed to data analysis, critical revision of the manuscript, and final manuscript approval. All authors read and approved the final version of the manuscript. All authors agreed to be accountable for all aspects of the work in ensuring that questions related to the accuracy or integrity of any part of the work are appropriately investigated and resolved.

Ethics approval and consent to participate

The study was approved by the Institutional Review Board of Nagoya University Graduate School of Medicine, Nagoya, Japan. The approval number of the study is 2014-0052-2. The approval date is February 14th, 2017. Requirement of written informed consent was waived due to the retrospective design of the study.

\section{Consent for publication}

Not applicable.

\section{Competing interests}

The authors declare that they have no competing interests.

\section{Publisher's Note}

Springer Nature remains neutral with regard to jurisdictional claims in published maps and institutional affiliations.

\section{Author details}

${ }^{1}$ Department of Respiratory Medicine, Nagoya University Graduate School of Medicine, 65 Tsurumai-cho, Showa-ku, Nagoya 466-8550, Japan. ²Department of Radiology, Nagoya University Graduate School of Medicine, Nagoya, Japan. ${ }^{3}$ Department of Preventive Medicine, Nagoya University Graduate School of Medicine, Nagoya, Japan. ${ }^{4}$ Department of Thoracic Surgery, Nagoya University Graduate School of Medicine, Nagoya, Japan.

Received: 4 March 2017 Accepted: 21 December 2017

Published online: 05 January 2018

\section{References}

1. Sekine $Y$, Behnia M, Fujisawa T. Impact of COPD on pulmonary complications and on long-term survival of patients undergoing surgery for NSCLC. Lung Cancer. 2002;37:95-101.

2. Matsuo M, Hashimoto N, Usami N, et al. Inspiratory capacity as a preoperative assessment of patients undergoing thoracic surgery. Interact Cardiovasc Thorac Surg. 2012;14:560-4.

3. Zhang J, Zhou JB, Lin XF, et al. Prevalence of undiagnosed and undertreated chronic obstructive pulmonary disease in lung cancer population. Respirology. 2013;18:297-302.

4. Osuka S, Hashimoto N, Sakamoto K, et al. Risk stratification by the lower limit of normal of FEV1/FVC for postoperative outcomes in patients with COPD undergoing thoracic surgery. Respir Investig. 2015;53:117-23.

5. Matsuzaki A, Hashimoto N, Okachi $S$, et al. Clinical impact of the lower limit of normal of FEV1/FVC on survival in lung cancer patients undergoing thoracic surgery. Respir Investig. 2016;54:184-92.

6. Hashimoto N, Matsuzaki A, Okada Y, et al. Clinical impact of prevalence and severity of COPD on the decision-making process for therapeutic management of lung cancer patients. BMC Pulm Med. 2014;14:14.

7. Kitano M, Iwano S, Hashimoto $N$, et al. Lobar analysis of collapsibility indices to assess functional lung volumes in COPD patients. Int J Chron Obstruct Pulmon Dis. 2014:9:1347-56.

8. Ueda K, Jinbo M, Li TS, et al. Computed tomography-diagnosed emphysema, not airway obstruction, is associated with the prognostic outcome of early-stage lung cancer. Clin Cancer Res. 2006;12:6730-6.

9. Sato $\mathrm{T}$, Teramukai $\mathrm{S}$, Kondo $\mathrm{H}$, et al. Impact and predictors of acute exacerbation of interstitial lung diseases after pulmonary resection for lung cancer. J Thorac Cardiovasc Surg. 2013:147:1604-1611.e1603.

10. Voltolini L, Bongiolatti $S$, Luzzi $L$, et al. Impact of interstitial lung disease on short-term and long-term survival of patients undergoing surgery for nonsmall-cell lung cancer: analysis of risk factors. Eur J Cardiothorac Surg. 2013; 43:e17-23.

11. Sato T, Watanabe A, Kondo $H$, et al. Long-term results and predictors of survival after surgical resection of patients with lung cancer and interstitial lung diseases. J Thorac Cardiovasc Surg. 2015;149:64-70 e62.

12. Vancheri C, Failla M, Crimi N, et al. Idiopathic pulmonary fibrosis: a disease with similarities and links to cancer biology. Eur Respir J. 2010;35:496-504.

13. Raghu G, Collard HR, Egan JJ, et al. An official ATS/ERS/JRS/ALAT statement: idiopathic pulmonary fibrosis: evidence-based guidelines for diagnosis and management. Am J Respir Crit Care Med. 2011;183:788-824. 
14. Hashimoto N, Iwano S, Kawaguchi K, et al. Impact of thin-section computed tomography-determined combined pulmonary fibrosis and emphysema on outcomes among patients with Resected lung cancer. Ann Thorac Surg. 2016;102:440-7.

15. Hunninghake GM. A new hope for idiopathic pulmonary fibrosis. N Engl J Med. 2014;370:2142-3.

16. Woodruff PG, Agusti A, Roche N, et al. Current concepts in targeting chronic obstructive pulmonary disease pharmacotherapy: making progress towards personalised management. Lancet. 2015;385:1789-98.

17. Okachi S, Imai N, Imaizumi K, et al. Endobronchial ultrasound transbronchial needle aspiration in older people. Geriatr Gerontol Int. 2013;13:986-92.

18. Okachi S, Imai N, Imaizumi $\mathrm{K}$, et al. Factors affecting the diagnostic yield of Transbronchial biopsy using Endobronchial Ultrasonography with a guide sheath in peripheral lung cancer. Intern Med. 2016;55:1705-12.

19. Rabe KF, Hurd S, Anzueto A, et al. Global strategy for the diagnosis, management, and prevention of chronic obstructive pulmonary disease: GOLD executive summary. Am J Respir Crit Care Med. 2007;176:532-55.

20. Detterbeck FC, Boffa DJ, Tanoue LT. The new lung cancer staging system. Chest. 2009:136:260-71.

21. Maeda R, Yoshida J, Ishii G, et al. The prognostic impact of cigarette smoking on patients with non-small cell lung cancer. J Thorac Oncol. 2011;6:735-42.

22. Cottin $V$, Nunes $H$, Brillet PY, et al. Combined pulmonary fibrosis and emphysema: a distinct underrecognised entity. Eur Respir J. 2005;26:586-93.

23. Goddard PR, Nicholson EM, Laszlo G, et al. Computed tomography in pulmonary emphysema. Clin Radiol. 1982;33:379-87.

24. Cottin V. The impact of emphysema in pulmonary fibrosis. Eur Respir Rev. 2013;22:153-7

25. Baldwin DR, White $B$, Schmidt-Hansen $M$, et al. Diagnosis and treatment of lung cancer: summary of updated NICE guidance. BMJ. 2011;342:d2110.

26. Brunelli A, Charloux A, Bolliger CT, et al. ERS/ESTS clinical guidelines on fitness for radical therapy in lung cancer patients (surgery and chemoradiotherapy). Eur Respir J. 2009;34:17-41.

27. Latsi PI, du Bois RM, Nicholson AG, et al. Fibrotic idiopathic interstitial pneumonia: the prognostic value of longitudinal functional trends. Am J Respir Crit Care Med. 2003;168:531-7.

28. Schmidt SL, Nambiar AM, Tayob N, et al. Pulmonary function measures predict mortality differently in IPF versus combined pulmonary fibrosis and emphysema. Eur Respir J. 2011;38:176-83.

29. Matsuo K, Iwano S, Okada T, et al. 3D-CT lung volumetry using multidetector row computed tomography: pulmonary function of each anatomic lobe. J Thorac Imaging. 2012;27:164-70.

30. Kitaguchi Y, Fujimoto K, Hayashi R, et al. Annual changes in pulmonary function in combined pulmonary fibrosis and emphysema: over a 5-yea follow-up. Respir Med. 2013;107:1986-92.

31. Kim YS, Jin GY, Chae KJ, et al. Visually stratified CT honeycombing as a survival predictor in combined pulmonary fibrosis and emphysema. $\mathrm{Br} \mathrm{J}$ Radiol. 2015;88:20150545

32. British Thoracic Society Society of Cardiothoracic Surgeons of Great Britain Ireland Working Party. BTS guidelines: guidelines on the selection of patients with lung cancer for surgery. Thorax. 2001;56:89-108.

33. Temel JS, Greer JA, Muzikansky A, et al. Early palliative care for patients with metastatic non-small-cell lung cancer. N Engl J Med. 2010;363:733-42.

34. Deepak JA, Ng X, Feliciano J, et al. Pulmonologist involvement, stage-specific treatment, and survival in adults with non-small cell lung cancer and chronic obstructive pulmonary disease. Ann Am Thorac Soc. 2015;12:742-51.

\section{Submit your next manuscript to BioMed Central and we will help you at every step:}

- We accept pre-submission inquiries

- Our selector tool helps you to find the most relevant journal

- We provide round the clock customer support

- Convenient online submission

- Thorough peer review

- Inclusion in PubMed and all major indexing services

- Maximum visibility for your research

Submit your manuscript at www.biomedcentral.com/submit 